\title{
Stump appendicitis
}

\author{
Rina P. Patel • J. Herman Kan
}

Received: 28 July 2008 /Revised: 1 October 2008 / Accepted: 10 October 2008 / Published online: 11 November 2008

(C) Springer-Verlag 2008

An 8-year-old boy presented 2 months after laparoscopic appendectomy with multiple episodes of right lower quadrant pain. A contrast-enhanced CT scan showed pericecal fat stranding (Fig. 1, asterisk) and tubular wall thickening (Fig. 1, arrows). A contrast-enhanced CT scan 3 months later showed more pronounced tubular wall thickening (Fig. 2, arrows) adjacent to an appendectomy clip (Fig. 2, arrowhead). Exploratory laparoscopy and histology revealed stump appendicitis.

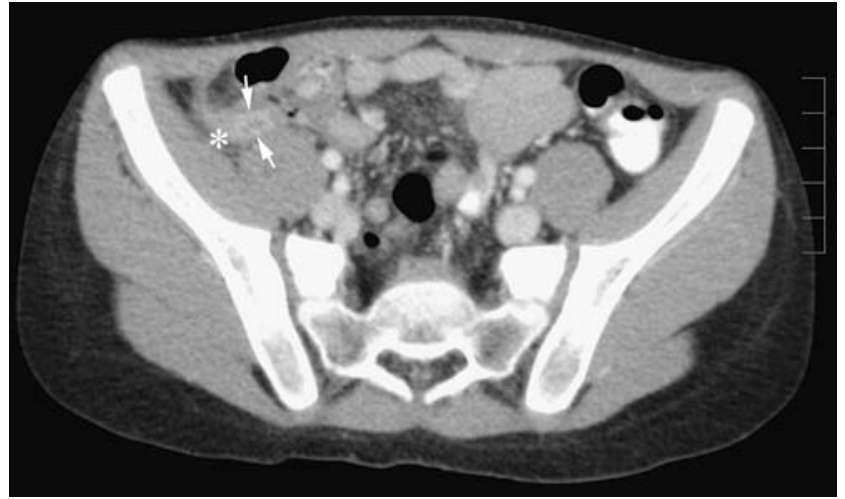

Fig. 1 Axial contrast-enhanced CT image obtained 2 months after initial appendectomy

R. P. Patel $(\bowtie)$

Vanderbilt University School of Medicine,

1211 Medical Center Drive,

Nashville, TN 37232, USA

e-mail: rina.p.patel@vanderbilt.edu

\section{J. H. Kan}

Department of Radiology and Radiological Sciences,

Vanderbilt Children's Hospital,

Nashville, TN, USA

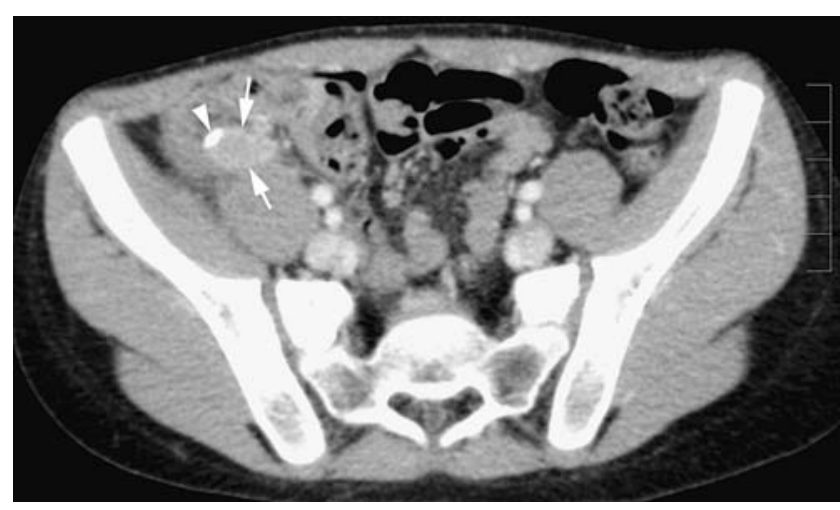

Fig. 2 Axial contrast-enhanced CT image obtained 5 months after initial appendectomy

Stump appendicitis is inflammation of residual appendiceal tissue after appendectomy and can occur months to years after the original operation. Inadequate visualization of the appendiceal-cecal junction can lead to longer stump length, a proposed risk factor for developing this condition and a theoretical risk related to laparoscopic technique [1]. The majority of reported cases (28/44) occurred following open appendectomy, but the number of cases related to laparoscopy likely will increase over time [2]. Stump appendicitis is infrequently included in the differential diagnosis for recurrent abdominal pain following appendectomy, and diagnosis may be delayed.

\section{References}

1. Mangi AA, Berger DL (2000) Stump appendicitis. Am Surg 66:739-741

2. Liang MK, Lo HG, Marks JL (2006) Stump appendicitis: a comprehensive review of literature. Am Surg 72:162-166 